\title{
Desiccation and cracking behavior of three compacted landfill liner soils
}

\author{
N. Yesiller , C.J. Miller G. Inci K. Yaldo
}

\begin{abstract}
Tests were conducted to investigate desiccation cracking of three compacted liner soils obtained from local landfills in southeast Michigan. The soils had low plasticity with varying fines content. Large-scale samples of the soils were subjected to wetting and drying cycles. Surficial dimensions of cracks and suction in the soils were monitored. Surficial dimensions of cracks were quantified using the crack intensity factor (CIF), which is the ratio of the surface area of cracks to the total surface area of a soil. All of the soils were subjected to a compaction-dry cycle (i.e. soils were allowed to dry after compaction) and a subsequent wet-dry cycle. An additional sample of one of the soils was subjected to a compaction-dry cycle and three wet-dry cycles. The maximum CIF obtained in the tests was $7 \%$ and suctions exceeding $6000 \mathrm{kPa}$ were recorded. It was observed that cracking was affected by the fines content of the soils. In general, high suctions, rapid increases in suctions, and high amount of cracking were observed in soils with high fines content, with less cracking observed in soil with low fines content. In addition, it was observed that cracking increased significantly due to addition of moisture to the soils. The CIF for wet-dry cycles were significantly greater than the CIF for compaction-dry cycles. Subsequent to moisture addition to the soils, critical suctions that caused a significant change in CIF during the drying cycles were $<1000 \mathrm{kPa}$ for all the soils. In the test with multiple wet-dry cycles, the amount of cracking did not change significantly after the second cycle.
\end{abstract}

\section{Introduction}

Cracking can adversely affect fine-grained soils. Cracks create zones of weakness in a soil mass and cause reductions in the overall strength and stability as well as increases in the compressibility of the soil. Structures that are constructed over fine-grained soils such as foundations and embankments can be affected by mechanical changes caused by cracking. Cracks can also create pathways for transport of fluids, which can significantly increase the hydraulic conductivity of the soils. Facilities that are constructed using fine-grained soils such as waste containment facilities and mine tailings dams can be affected by hydraulic changes resulting from cracking. Development of cracks can be due to various processes including desiccation and shrinkage, freezing and thawing, syneresis, differential settlement, and penetration by plant roots.

Desiccation cracks form as a result of water 
loss to the atmosphere from a drying soil mass. Drying causes shrinkage and subsequent cracking of the soil. In particular, fine-grained soils are affected by desiccation cracking. Mitchell (1993) indicates that type and amount of clay minerals present in a drying soil control desiccation cracking. The extent and rate of cracking is dependent on various factors including negative pore water pressures (suction) which develop in a soil during drying, and elastic properties of the drying soil (Morris et al., 1992; Fredlund and Rahardjo, 1993). In addition, moisture and density conditions, confining pressures, temperature, and cycles of wetting and drying affect desiccation cracking (Morris et al., 1992; Mitchell, 1993).

This study was conducted to investigate desiccation cracking of local soils used for construction of compacted soil liners in southeast Michigan. Large-scale samples of the soils were subjected to wetting and drying cycles. Surficial dimensions of cracks and magnitude of soil suctions were monitored during the cycles. The amount of cracking on the surface of the soils was quantified using an image analysis method. The changes in the amount of cracking with soil suction was investigated. In addition, critical suctions that caused a significant change in the amount of cracking were determined.

\section{Background}

Capillary forces associated with soil moisture loss to the atmosphere cause a soil mass to shrink. Suction develops in the soil due to drying. This suction increases the effective stresses (i.e. intergranular stresses) in the soil. In turn, volume of the soil starts decreasing and cracks develop in the soil mass. Cracking progresses with increasing suctions in a drying soil mass. Fine-grained soils are more susceptible to the development of cracks than coarse-grained soils due to the presence of small pores, which allow for the development of high suctions (Holtz and Kovacs, 1981; Mitchell, 1993). Adding coarse-grained materials to clay soils can reduce the amount of shrinkage and cracking significantly (DeJong and Warkentin, 1965; Kleppe and Olson, 1985), although this might change the engineering properties of the soils.

The presence of high amounts of clay particles in a soil, particularly highly active clay minerals such as smectites and vermiculites, promotes the formation of cracks (Holtz and Kovacs, 1981; Mitchell, 1993). A high plasticity index (PI) and low shrinkage limit indicates high potential for shrinkage and swelling. For PI $>35$, excessive shrinkage can be expected (Daniel, 1991). The chemistry of the pore fluid also affects crack formation.

For compacted clay soils, compaction conditions affect the desiccation behavior of the soil. Daniel and $\mathrm{Wu}$ (1993) recommend compaction at low water contents (dry of optimum) using great effort to minimize potential for cracking in arid areas. However, a soil compacted in this manner may swell extensively if it comes in contact with water and this soil may then shrink excessively upon subsequent drying. Holtz and Kovacs (1981) indicate that compaction at wet of optimum and at low densities can reduce swelling. However, a soil compacted in this manner can shrink and dessicate excessively if it is subjected to drying. Hence, compaction conditions tend to promote either low shrinkage or low swelling.

Albrecht (1996) conducted tests on 11 compacted clay soils to determine the effects of wetting and drying cycles on soil hydraulic conductivity. Large increases occurred in the hydraulic conductivity of high-plasticity soils compacted at wet optimum water contents due to wetting and drying cycles. However, small changes occurred in the conductivity of the soils compacted at dry of optimum water contents due to the cycles. Albrecht (1996) stated that this difference resulted from the presence of large cracks in the wet of optimum soils due to drying. The hydraulic conductivity of low-plasticity soils at the wet and dry of optimum water contents did not vary significantly.

In the study conducted by Kleppe and Olson (1985), the cracking level was determined for compacted clay soils prepared with two different moisture conditions. In the first set of tests, samples of compacted clay soils were allowed to dry immediately after compaction. In the second set of tests, samples of the same clay soils were 
compacted and then saturated prior to drying. The saturated samples cracked more than the unsaturated soils (Kleppe and Olson, 1985). Increases in the water content of similar compacted soils increased desiccation cracking.

Observations of cracking of compacted liner soils in the field have been presented in various studies. Basnett and Brungard (1992) observed desiccation cracks on the side slopes of a clay liner during landfill construction. The cracks were 13 $25 \mathrm{~mm}$ in width and extended to a depth of $0.30 \mathrm{~m}$. Miller and Mishra (1989) observed desiccation cracks during their field investigation of landfill liners. The cracks exceeded $10 \mathrm{~mm}$ in width and some penetrated the entire depth $(0.30 \mathrm{~m})$ of the compacted clay layer. Montgomery and Parsons (1989) observed desiccation cracking at test plots simulating covers constructed at a landfill in Wisconsin. Subsequent to 3 years of exposure, the upper $0.20-0.25 \mathrm{~m}$ of the compacted clay plots had become desiccated, with crack widths exceeding $13 \mathrm{~mm}$. Maximum crack depths of $1.0 \mathrm{~m}$ were reported at a number of locations in the test plots. Corser and Cranston (1991) reported observations of cracks extending to $0.10 \mathrm{~m}$ depth within the compacted cover sections from a test fill in an arid part of California.

\subsection{Quantification of cracking}

Crack dimensions are generally measured using approximate methods. In most cases, qualitative descriptions are provided to estimate the extent of cracking. The irregular shape and complex geometry of cracks prevent accurate measurements of length, width, and depth. The width and depth of cracks are not uniform along the length of a crack. Maximum length, width, and depth are commonly recorded using measurements with rulers and/or thin gauge wires. Kleppe and Olson (1985) developed a scale that ranged from 0 to 4 to describe severity of cracking. A crack severity number of 0 indicates absence of cracking, whereas, cracks with widths $>20 \mathrm{~mm}$ and with substantial depths are described by a crack severity number of 4 .

Al Wahab and El-Kedrah (1995) developed a cracking index to quantify the extent of cracking. The cracking index is the ratio of the area of cracks to the total surface area of a soil. The area of a crack is equal to the product of its length and width. Calculations were made for crack depths exceeding $2 \mathrm{~mm}$. Al Wahab and El-Kedrah (1995) did not present methods for the determination of the length and width of cracks. It is believed that these dimensions were determined using a ruler. This potentially leads to overlooking the effects of the irregular shape of cracks in the calculation of the cracking index.

Mi (1995) and Miller et al. (1998) described a similar approach. The crack intensity factor (CIF) was introduced as a descriptor of the extent of surficial cracking. CIF is defined as the ratio of area of cracks $\left(A_{\mathrm{c}}\right)$ to the total surface area $\left(A_{\mathrm{t}}\right)$ of a drying soil mass. A computer aided image analysis program was used to determine the CIF values. The areas were determined using photographs of desiccating soils. Cracks appear darker than remaining uncracked soil surface in photographs of a drying soil. The contrast between the color of the cracks and the uncracked soil is used to calculate the CIF. Scanned photographs of soil surfaces were analyzed using MATLAB ${ }^{\circledR}$ to determine CIF. In this study, CIF was used to quantify the amount of cracking in compacted clay soils.

\subsection{Cycles of shrinkage and swelling}

Shrinkage during the first drying cycle in a clay soil causes irreversible fabric changes (Yong and Warkentin, 1975). Particle bonds may be broken during this cycle effectively weakening the soil. Upon wetting, the rearranged soil structure will be further weakened by the addition of water. Subsequent drying will again cause shrinkage. Cracking will occur during this drying cycle at the weakest locations of the soil structure. Yong and Warkentin (1975) stated that cracking will occur at locations with low cohesion, which can correspond to the wettest locations in the soil. The broken bonds caused during the first drying cycle may attract water and become preferential zones of cracking.

Effects of cyclic shrinkage and swelling were investigated in a number of studies. Al Wahab and El-Kedrah (1995) reported the results of tests conducted on a compacted clay with a medium- 
high plasticity. They observed that the amount of cracking (measured using the cracking index) did not change significantly after three wetting and drying cycles. Omidi et al. (1996) reported results of hydraulic conductivity tests conducted on compacted clay soils that had undergone two wetting and drying cycles. Outflow rates were correlated to the crack formation. As the extent of cracking increased, the flow through the test samples also increased. Tests conducted on samples of clay soils containing smectite or illite minerals showed that outflow rates continued to increase at the end of the second cycle. This indicated that cracking was still in progress at the end of the second wetting and drying cycle for these soils. However, samples obtained by mixing the natural soils with $30 \%$ sand had very similar outflow rates at the end of the first and second cycles. This indicated that the extent of cracking did not change subsequent to the first cycle.

Albrecht (1996) observed that the hydraulic conductivity of low-plasticity soils increased due to a single wetting and drying cycle and remained constant after the first cycle. However, the hydraulic conductivity of high-plasticity soils continued to increase up to the end of the second wetting and drying cycle.

\section{Testing program}

Large-scale tests were conducted to analyze the desiccation and cracking behavior of three compacted liner soils. The soils were subjected to wetting and drying cycles. Changes in soil suction and surficial characteristics of cracks were monitored during the wetting and drying cycles.

\subsection{Experimental setup}

The experimental setup consisted of a soil tank, a rainfall simulation system, a drying system, a surface crack recording system, and probes for measuring suction (Fig. 1). Soils used in the study were compacted in a steel reinforced plexiglas tank. Dimensions of the tank were $1.0 \mathrm{~m}$ length, $1.5 \mathrm{~m}$ width, and $0.5 \mathrm{~m}$ depth. A rainfall nozzle and fans were used for cyclic wetting and drying of the soils. A rainfall simulation system consisting of a pipe, regulator, flow meter, pressure gauge, and water spraying nozzle was positioned over the tank. The oscillation of the nozzle was controlled electronically to provide complete and regular coverage of the entire tank. When the soil in the tank was allowed to dry, three fans (mounted on the walls of the tank above the soil surface) were used

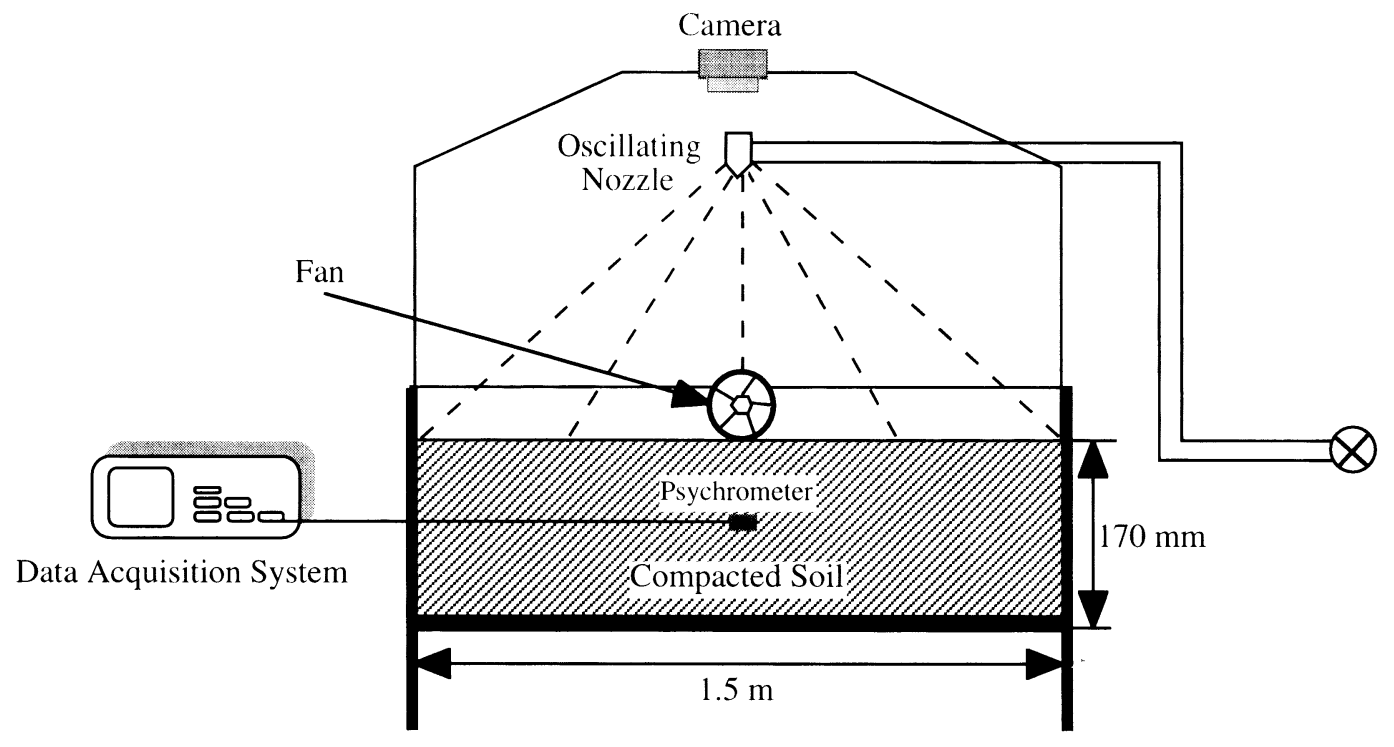

Fig. 1. Test setup. 
Table 1

Soil characterization

\begin{tabular}{|c|c|c|c|}
\hline Property (1) & Soil 1 (2) & Soil 2 (3) & Soil 3 (4) \\
\hline Specific gravity & 2.70 & 2.70 & 2.73 \\
\hline \multicolumn{4}{|l|}{ Particle size analysis } \\
\hline$\%$ Sand & 25 & 19 & 68 \\
\hline$\%$ Silt & 45 & 39 & 21 \\
\hline$\%$ Clay & 30 & 42 & 11 \\
\hline \multicolumn{4}{|l|}{ Atterberg limits } \\
\hline LL & 22 & 29 & 17 \\
\hline PP & 6 & 16 & 6 \\
\hline USCS Classification & CL-ML & $\mathrm{CL}$ & SM-SC \\
\hline \multicolumn{4}{|l|}{ Compaction } \\
\hline Optimum water content $(\%)$ & 13 & 11 & 12 \\
\hline Maximum dry unit weight $\left(\mathrm{kN} \mathrm{m}^{-3}\right)$ & 19.3 & 19.7 & 19.8 \\
\hline Hydraulic conductivity $\left(\mathrm{cm} \mathrm{s}^{-1}\right)$ & $1.1 \times 10^{-8}$ & $7.8 \times 10^{-8}$ & $1.0 \times 10^{-7}$ \\
\hline
\end{tabular}

to simulate wind action on the soil surface and to increase the rate of air drying.

A $35 \mathrm{~mm}$ camera was mounted $1.2 \mathrm{~m}$ above the tank to record periodic images of the soil surface undergoing cyclic wetting and drying. Psychrometers (Wescor ${ }^{\circledR}$ Model P55) were used to measure suction in the soils. Psychrometers were selected for the suction measurements in this study because very dry conditions were expected. In these applications, tensiometers are inappropriate due to air entry problems at suctions $>100 \mathrm{kPa}$. Suctions up to $7000 \mathrm{kPa}$ have been measured using psychrometers (Fredlund and Rahardjo, 1993). These suctions correspond to very dry soil conditions. A total of six evenly spaced psychrometers were placed at the middepth of the soil in the tank. The psychrometers were connected to a data logger (Wescor ${ }^{\circledR}$ Model HP-115) for continuous recording of the suctions.

\subsection{Materials}

Soils used in the study were obtained from three landfills located in southeast Michigan. The soil characterization data is presented in Table 1 . The mineralogical composition of Soil 1 is presented in Table 2. Salim (1994) indicated that the mineralogy of this soil was very similar to the mineralogi- cal composition of three other liner soils obtained in this geographical region. Therefore, it is assumed that Soils 2 and 3 were similar to Soil 1 in composition with high amounts of illite and low amounts of kaolinite and chlorite in the clay fraction. In general, highly active minerals such as

Table 2

Mineralogical composition of Soil 1

\begin{tabular}{llc}
\hline $\begin{array}{l}\text { Soil fraction } \\
(1)\end{array}$ & Mineral type & $\begin{array}{l}\text { Amount (\% by weight) } \\
(2)\end{array}$ \\
\hline Clay & Chlorite & 8 \\
& Illite & 63 \\
& Hornblende & 3 \\
& Kaolinite & 11 \\
& Microcline & 6 \\
& Quartz & 5 \\
Silt & Plagioclase & 4 \\
& Chlorite & 3 \\
& Illite & 3 \\
& Quartz & 56 \\
& Albite & 6 \\
& Calcite & 21 \\
Sand & Dolomite & 11 \\
& Quartz & 90 \\
& Calcite & 7 \\
& Dolomite & 3
\end{tabular}


smectites and vermiculites are not present in the soils of this region.

\subsection{Procedure}

The testing program consisted of two main steps; soil preparation and compaction; and wetting and drying cycles.

\subsubsection{Soil preparation and compaction}

All the soils used in the study were wetted to approximately the optimum water content $( \pm 2 \%)$. The wetted soil was left in sealed boxes for 2 days of hydration to promote uniform water absorption. Prior to compaction, large soil clods were broken down into smaller clods (maximum equivalent diameter $<10 \mathrm{~mm}$ ). The loose soil was then placed in the plexiglas tank and compacted using a square steel pad $(0.25 \mathrm{~m} \times 0.25 \mathrm{~m})$ with a weight of $96 \mathrm{~N}$. The pad was lifted $0.6 \mathrm{~m}$ and dropped freely to the soil surface. The soils were compacted in three equal lifts of approximately $60 \mathrm{~mm}$ thickness. Compaction energy was equal to the compaction energy used in standard Proctor compaction tests, $593 \mathrm{~kJ} \mathrm{~m}^{-3}$. Final depth of the soil in the tank was $170 \mathrm{~mm}$. Water content and dry unit weight of soils were determined at completion of the compaction, before the initiation of cyclic wetting and drying tests. Water contents were determined to be 11, 11.5, and $11.3 \%$ for Soils 1, 2 , and 3, respectively. Dry unit weights were determined to be $17.9,18.7$, and $18.8 \mathrm{kN} \mathrm{m}^{-3}$ for Soils 1, 2, and 3, respectively.

\subsubsection{Wetting and drying cycles}

Initially, all soils were subjected to two cycles: a compaction-dry cycle and a wet-dry cycle. The compaction-dry cycle consisted of the drying period immediately after compaction. The compaction-dry cycle ended when the suction was stabilized at a constant value or increased above $6000 \mathrm{kPa}$, the upper limit for reliable measurements with the psychrometers used in this study. Wetting and drying cycles started subsequent to the compaction-dry cycle. The wetting cycle started with the application of simulated rainfall to the dry soil. The rainfall was applied at a rate of approximately $25 \mathrm{~mm} \mathrm{~h}^{-1}$. Rainfall application was terminated when the ponded water level above the soil surface reached $25 \mathrm{~mm}$ or at the end of $2 \mathrm{~h}$ of application, regardless of the depth of the ponded water. In most cases, this provided sufficient water to completely saturate the soil. The soil tank was sealed with a glass cover during the infiltration phase to prevent evaporation of moisture. The end of a wetting cycle was defined as decrease of suction to a value below $500 \mathrm{kPa}$, in most cases to $0 \mathrm{kPa}$ (i.e. saturation of the soil). When the wetting cycle was completed, the soil was again allowed to dry. Fans on the sides of the tank were used for the drying cycle. Similar to the compaction-dry cycle, the end of a drying cycle was defined as the stabilization of the suction at a constant value or increase of suction above $6000 \mathrm{kPa}$.

It was expected prior to testing that highest amount of cracking would occur in Soil 2 due to its higher plasticity compared with the other soils. Therefore, this soil was selected for further analysis of cracking. An additional sample of the soil was subjected to second and third wetting and drying cycles in addition to the compaction-dry cycle and the first wet-dry cycle. The second and third cycles were initiated and terminated using the criteria described above.

Photographs of the soils were taken at varying intervals during all stages of the tests. At the beginning of a wetting or drying cycle images of the soil surface were recorded at short intervals, usually $<1 \mathrm{~h}$. At the end of a wetting or drying cycle images of the soil surface were recorded at long intervals $(>24 \mathrm{~h})$, because less change occurred on the surface of the soils at the end of a cycle than at the beginning of a cycle.

\section{Results and discussion}

Initially, variations in soil suction and CIF with time were analyzed. Variation of the extent of cracking on the surface of the soils with suction was then analyzed using CIF values.

\subsection{Variations in suction and CIF with time}

Soil suctions obtained during compaction-dry and wet-dry cycles are presented in Fig. 2. Suction 


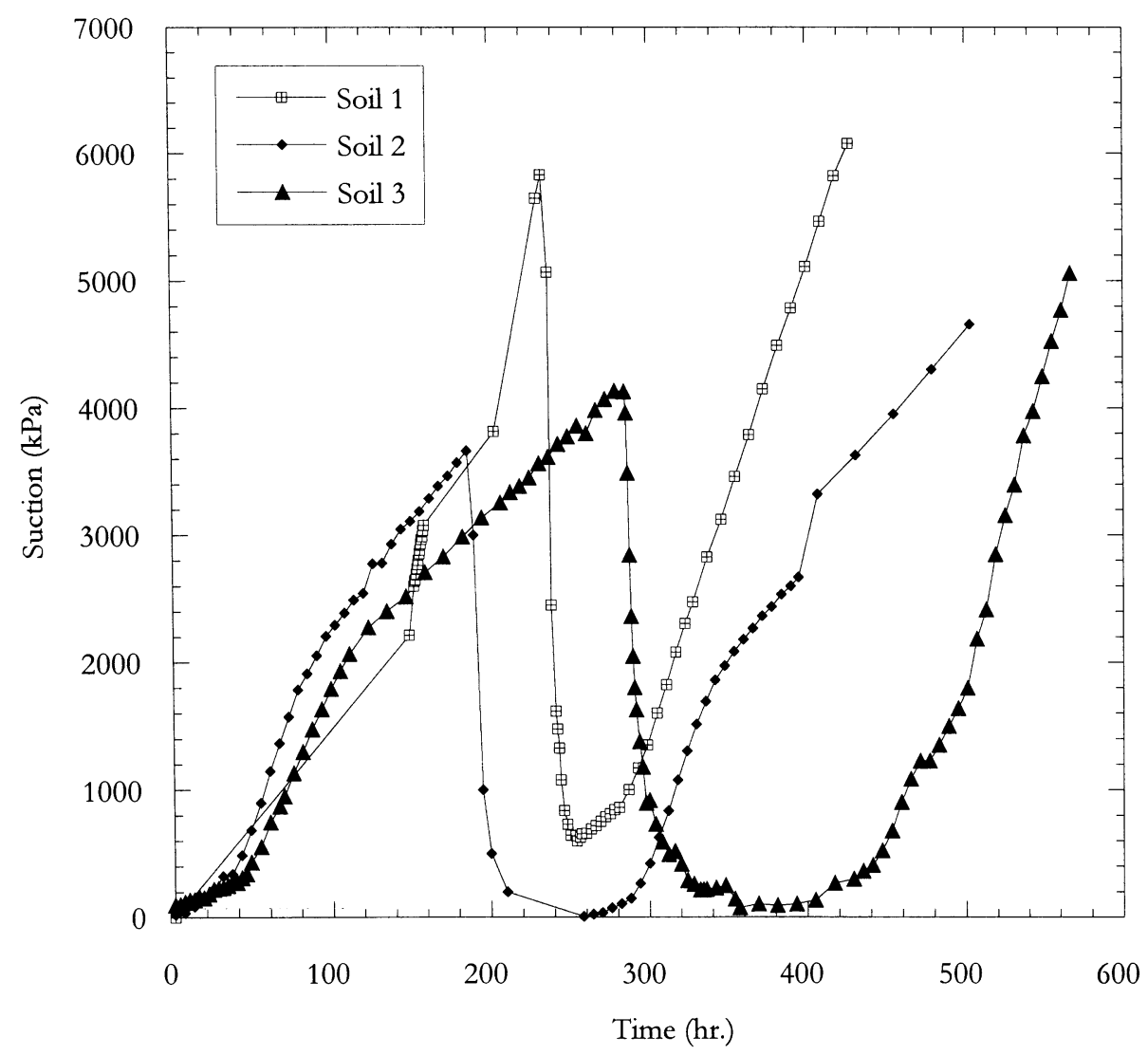

Fig. 2. Variation of suction with time for Soils 1-3 for compaction-dry and wet-dry cycles.

in Soil 1 was higher than suction in Soils 2 and 3. Suction in Soil 1 reached $6000 \mathrm{kPa}$ in both compaction-dry and wet-dry cycles. Suction in Soils 2 and 3 reached approximately 4000 and $5000 \mathrm{kPa}$ in compaction-dry cycles and wet-dry cycles, respectively. Suction in Soils 1 and 2 increased more rapidly than suction in Soil 3 during both compaction-dry and wet-dry cycles. Changes in suction during the wetting period occurred faster than the changes during the drying periods.

Soils 1 and 2 have 75 and $81 \%$ fines content $(\%$ fines $=\%$ silt $+\%$ clay $)$, respectively, and Soil 3 has $32 \%$ fines content. In general, high suctions and fast increases in suction were obtained for the soils with high fines content. Higher suctions are associated with smaller pore sizes. Small pores are expected to develop in compacted soils with high amounts of fine particles. As the pore sizes decrease, high suctions develop easily in the soil mass.

A new sample of Soil 2 was prepared and subjected to three wetting and drying cycles subsequent to a compaction-dry cycle (Fig. 3). Suction in the soil reached $3700 \mathrm{kPa}$ during the compaction-dry cycle. Suction reached approximately $5000 \mathrm{kPa}$ in the first and third drying cycles and $5700 \mathrm{kPa}$ in the second cycle.

In Figs. 2 and 3, it was observed that suctions in the soils were higher after the first wetting period compared with the suctions obtained in the compaction-dry period. It is believed that the soils experienced shrinkage and irreversible fabric changes during the first time they were dried (compaction-dry cycle) similar to the observations 


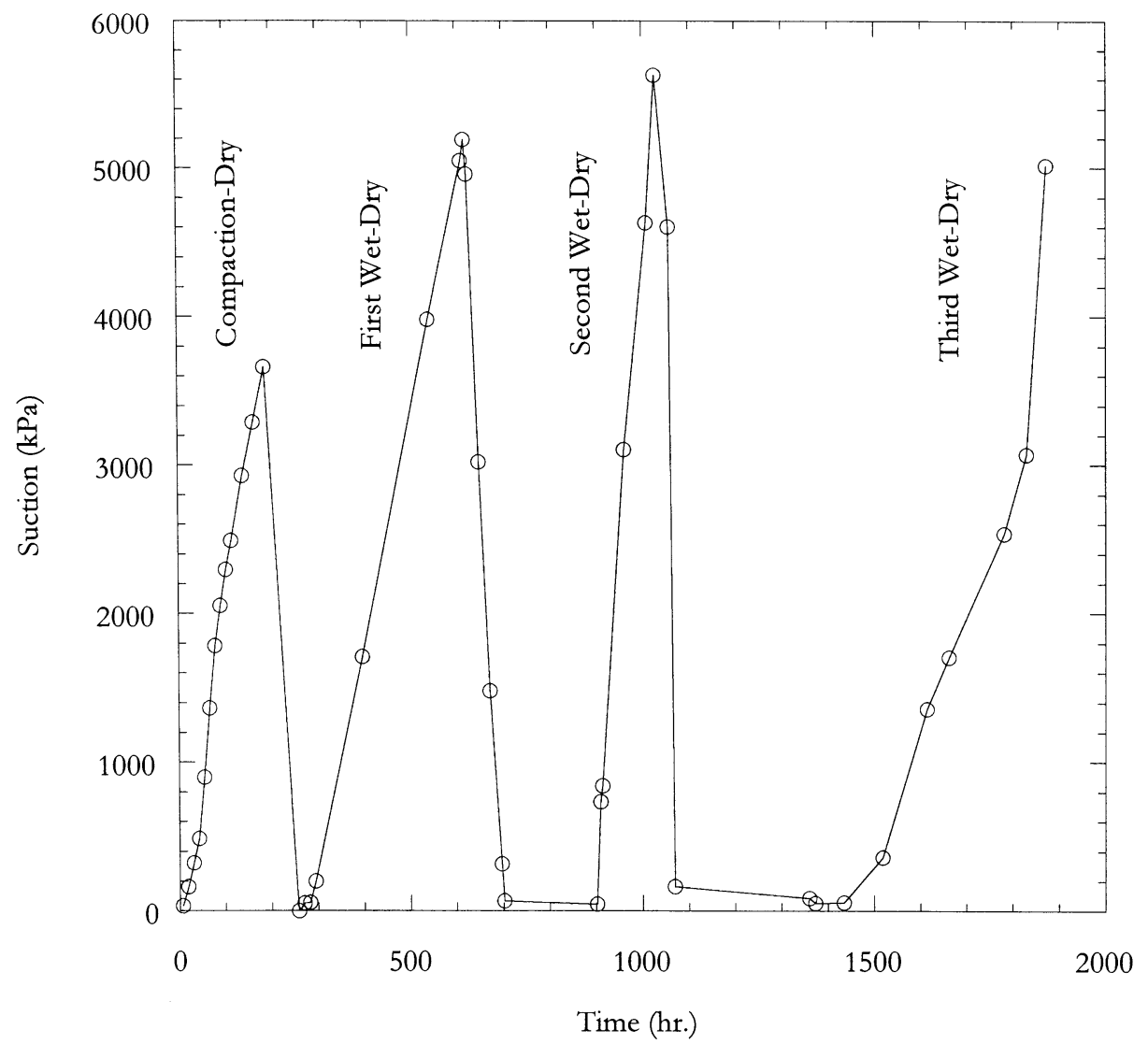

Fig. 3. Variation of suction with time for Soil 2 in the multiple cycle tests.

of Yong and Warkentin (1975). The shrinkage caused decreases in the size of the pore spaces and resulted in increased suction in the subsequent drying periods (e.g. first wet-dry cycles).

CIF was calculated using a number of photographs obtained in a cycle. CIF for the soils due to compaction-dry and wet-dry cycles is presented in Fig. 4. During the compaction-dry period the CIF was low. The CIF increased significantly after the first wetting period. Less than $1 \%$ of the surface area of Soils 1 and 2 were cracked (i.e. CIF $<1 \%$ ) subsequent to the compaction-dry cycle (Fig. 4). Essentially no cracking (i.e. $\mathrm{CIF}=0 \%$ ) was observed in Soil 3 in this cycle. After the wet-dry cycle, CIF in Soil 1 was 5.5\% indicating that 5.5\% of the surface area of the soil was covered with cracks. The CIF was 5 and $2.5 \%$ for Soils 2 and
3 , respectively, at the end of the same period (Fig. 4). The CIF in Soils 1 and 2 was higher than the CIF in Soil 3.

It was observed that the fines content was related to the CIF. The high CIFs were obtained for the soils with the high fines content. The lowest CIF was obtained for the soil with the lowest fines content. Although Soils 1 and 3 had the same PI, their cracking behavior was not similar. The difference in the CIF for these two soils is explained by the amount of fine particles in these soils. Prior to testing, it was expected that the cracking in the soils be correlated to the PI of the soils. However, it was observed that fines content was more important in the cracking behavior of the soils than the PI. It is believed that small pores that allow the development of high suctions were formed in the 


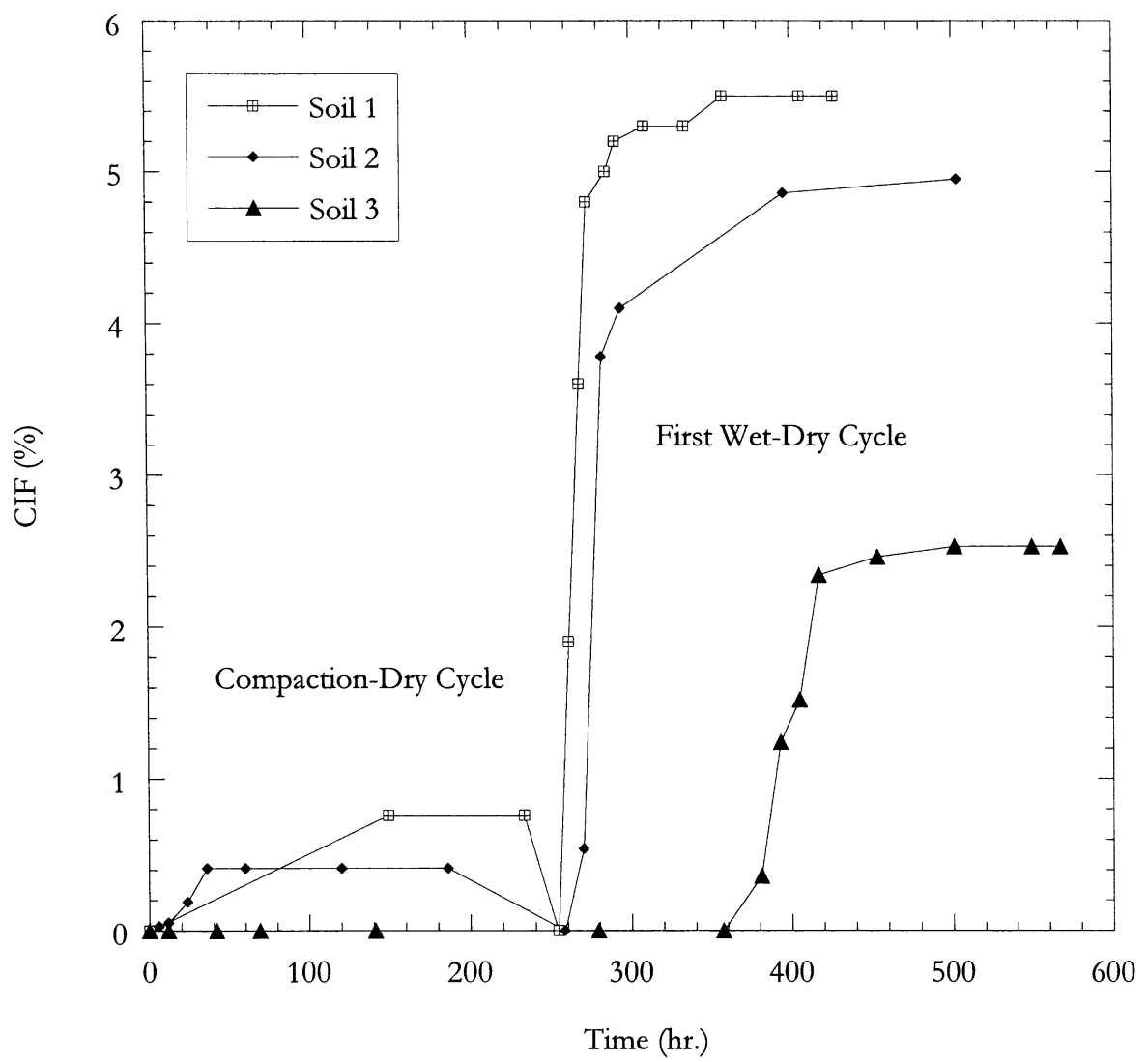

Fig. 4. Variation of CIF with time for Soils 1-3 for the compaction-dry and wet-dry cycles.

soils with a high fines content. However, a sufficient amount of small pores that allow the development of high suctions did not form in the soil with a low fines content.

Cracks developed rapidly in the soils at the beginning of a drying cycle (e.g. for Soil 1, CIF increased from 0 to $4.8 \%$ in 1.5 days). Cracking progressed slowly after the initial rapid crack development period (e.g. for Soil 1, CIF increased from 4.8 to $5.5 \%$ in 5 days and essentially remained at this value for the subsequent 3 days). A similar behavior was observed for all the soils (Fig. 4). The suctions that cause the rapid development of cracks are referred to as critical suctions and they are explained in detail in Section 4.2.

The CIF data for Soil 2 for the compactiondry and three wet-dry cycles are presented in
Fig. 5. CIF increased to $5 \%$ in the first wet-dry cycle. The CIF reached 6.9 and $6.7 \%$ in the second and third wet-dry cycles, respectively. The CIF did not change significantly between the second and third cycles. Similar to data presented in Fig. 4, the CIF increased quickly at the beginning of a drying period and the progression of cracking slowed down after this initial period. The initial crack development period was 1.5 days and 0.5 days for the first and second cycles, respectively. CIF did not decrease to $0 \%$ subsequent to the second wet-dry cycle, because water application on the soil surface did not result in closing all of the cracks. At the start of third cycle, CIF was $2.3 \%$ and increased to its maximum value for this cycle $(6.7 \%)$ over a 5 day period (Fig. 5).

At the beginning of the compaction-dry period 


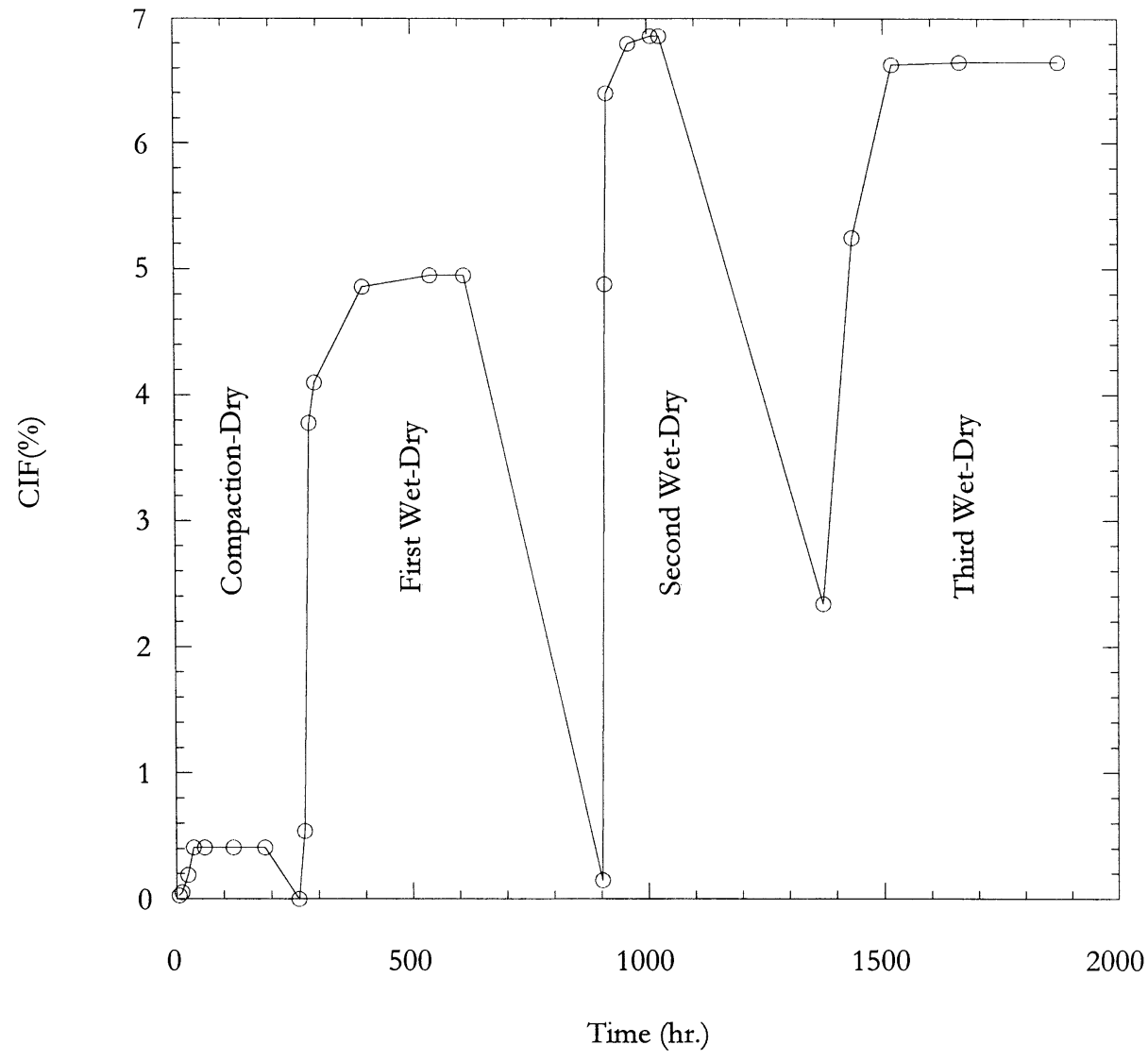

Fig. 5. Variation of CIF with time for Soil 2 in the multiple cycle tests.

the soil strength is near maximum for the given compaction conditions. This high strength results in high resistance to cracking, as the soil can resist the large tensile stresses associated with the high values of measured suction. Shrinkage due to drying causes structural rearrangement of soil particles and potential breaking of bonds (Yong and Warkentin, 1975). Upon wetting, the soil experiences softening and a decrease in strength. Subsequent drying induces suctions, which exceed the resistance of weakened soils easily. Hence, cracks develop at locations of decreased soil strength. It is believed that the rearrangement of soil fabric diminishes and eventually ceases subsequent to one or two wetting and drying cycles. Therefore, the extent of cracking does not change significantly subsequent to the first or second cycles (e.g. Fig. 5, subsequent to the first wet-dry cycle).

\subsection{Variation of CIF with suction}

Suction versus CIF for all the soils for compaction-dry and wet-dry cycles is presented in Fig. 6. For the wet-dry cycle, CIF in the soils increased significantly due to relatively small changes in suction $(<1000 \mathrm{kPa})$. In this cycle, $80-90 \%$ of cracking occurred before suction reached $1000 \mathrm{kPa}$. Suction increased significantly to $6000 \mathrm{kPa}$ for Soil 1 and approximately $5000 \mathrm{kPa}$ for Soils 2 and 3 at the end of the wet-dry cycle. However, cracking in the soils did not progress significantly beyond the initial cracking.

Suction versus CIF for Soil 2 for the compaction-dry and three wet-dry cycles is presented in Fig. 7. In the compaction-dry period, suction increased to $3700 \mathrm{kPa}$. However, a small amount of cracking $(<0.5 \%)$ was observed in the soil. In 


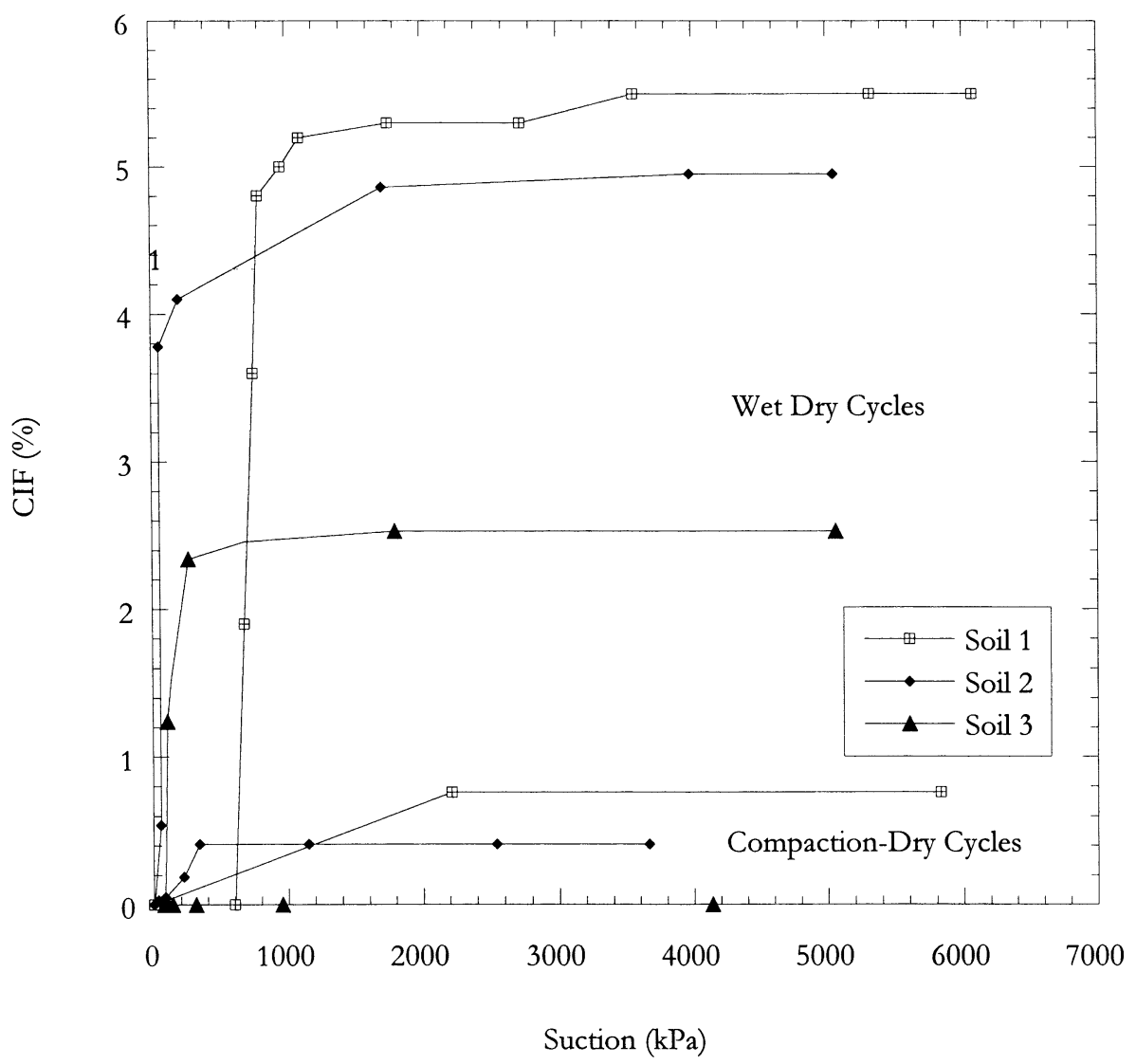

Fig. 6. Variation of CIF with suction for Soils 1-3 for the compaction-dry and wet-dry cycles.

the wet-dry cycles, CIF in the soils increased significantly due to relatively small changes in suction $(<1000 \mathrm{kPa})$. In this initial cracking period, $70-99 \%$ of total cracking in the soil occurred before suction reached $1000 \mathrm{kPa}$. Suction increased to 5000 and $5700 \mathrm{kPa}$ in these cycles. However, cracking did not progress significantly after initial cracking.

Suction versus CIF graphs (Figs. 6 and 7) indicate that cracking in the soils used in this study initiates and progresses significantly at suctions below $1000 \mathrm{kPa}$. Suction in the soils can increase above $5000 \mathrm{kPa}$, however, the extent of cracking does not necessarily increase significantly due to large increases in suction. The suction associated with the initial increase in CIF is identified as critical suction in the soils. Critical suction values for varying wet-dry cycles are presented in Table 3. In all cases, the critical suction is $<1000 \mathrm{kPa}$. It must be noted that critical suction values are provided for cycles subsequent to compaction-dry cycles. This is because significant amount of cracking did not occur in the soils in this cycle although suctions well above $1000 \mathrm{kPa}$ were measured.

The extent of cracking is a function of both the amount of water in the soil at the onset of drying and suction attained during drying. The extent of cracking was observed to be more directly correlated to water content than suction (Figs. 6 and 7). At similar suction levels during the drying period, more cracking occurred subsequent to wetting than subsequent to compaction. The high amount of water in the soils resulted in high amount of cracking. In addition, significant crack- 


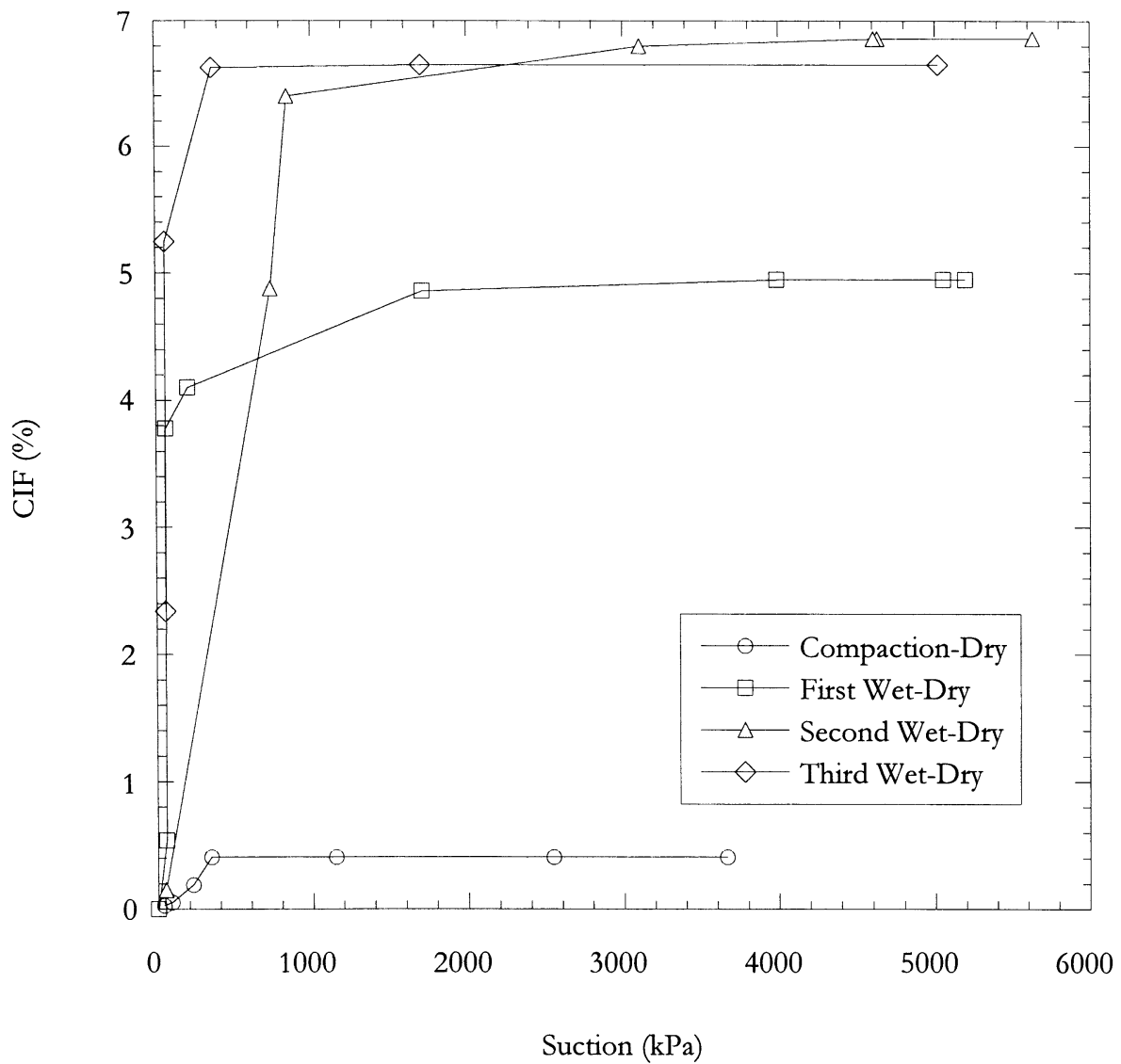

Fig. 7. Variation of CIF with suction for Soil 2 in the multiple cycle tests.

ing occurred in the soils at low suctions $(<1000 \mathrm{kPa})$ after the addition of water (compaction-dry versus wet-dry cycles). This can be explained by weakening the soils due to wetting and a resulting decrease in resistance to cracking (Yong and Warkentin, 1975).

Table 3

Critical suction

\begin{tabular}{lll}
\hline $\begin{array}{l}\text { Soil type } \\
(1)\end{array}$ & $\begin{array}{l}\text { Cycle } \\
(2)\end{array}$ & $\begin{array}{l}\text { Critical suction } \\
(\mathrm{kPa})(3)\end{array}$ \\
\hline 1 & 1st wet-dry & 800 \\
2 & 1st wet-dry & 200 \\
3 & 1st wet-dry & 300 \\
2 & 1st wet-dry (second test) & 200 \\
2 & 2nd wet-dry (second test) & 750 \\
2 & 3rd wet-dry (second test) & 350 \\
\hline
\end{tabular}

The results of all of the tests are summarized in Table 4. CIF values and corresponding test cycles, test times, and suctions for the end of each period of wetting and drying are provided in this table.

\subsection{Visual observations}

Visual observations of cracking in the soils indicated that cracking started with linear cracks in the compaction-dry period. The cracks became polygonal in the subsequent wet-dry cycles. Examples of photographs of drying in Soil 2 during the test with multiple cycles (compaction-dry cycle and three wet-dry cycles) are presented in Fig. 8. The entire surface area of the soil $(1 \mathrm{~m} \times 1.5 \mathrm{~m})$ is shown in the photographs. CIF values are also presented in Fig. 8. Cracks appeared at the same 
Table 4

CIF obtained in the tests

\begin{tabular}{|c|c|c|c|c|}
\hline Soil type (1) & CIF (\%) (2) & Cycle (3) & Time (h) (4) & Suction $(\mathrm{kPa})(5)$ \\
\hline 1 & 0.76 & compaction-dry & 233 & 5828 \\
\hline 1 & 0 & 1st wet-dry ${ }^{\mathrm{a}}$ & 254 & 598 \\
\hline 1 & 5.5 & 1st wet-dry ${ }^{\mathrm{b}}$ & 427 & 6075 \\
\hline 2 & 0.38 & compaction-dry & 186 & 3663 \\
\hline 2 & 0 & 1st wet-dry ${ }^{\mathrm{a}}$ & 258 & 6 \\
\hline 2 & 4.95 & 1st wet-dry ${ }^{\mathrm{b}}$ & 503 & 4658 \\
\hline 3 & 0 & compaction-dry & 279 & 4135 \\
\hline 3 & 0 & 1st wet-dry ${ }^{\mathrm{a}}$ & 357 & 76 \\
\hline 3 & 2.53 & 1st wet-dry ${ }^{\mathrm{b}}$ & 567 & 5059 \\
\hline 2 & 0.41 & compaction-dry & 180 & 3693 \\
\hline 2 & 0 & 1st wet-dry (second test) ${ }^{\mathrm{a}}$ & 258 & 0 \\
\hline 2 & 4.95 & 1st wet-dry (second test) ${ }^{\mathrm{b}}$ & 618 & 5194 \\
\hline 2 & 0.15 & 2nd wet-dry (second test) ${ }^{\mathrm{a}}$ & 902 & 48 \\
\hline 2 & 6.86 & 2nd wet-dry (second test) ${ }^{\mathrm{b}}$ & 1027 & 5632 \\
\hline 2 & 2.34 & 3 rd wet-dry (second test) ${ }^{\mathrm{a}}$ & 1373 & 54 \\
\hline 2 & 6.65 & 3 rd wet-dry (second test) ${ }^{\mathrm{b}}$ & 1872 & 5019 \\
\hline
\end{tabular}

${ }^{a}$ At the end of the wetting period.

${ }^{\mathrm{b}}$ At the end of the drying period.

locations as the first drying period in the second and third cycles (Fig. 8). Subsequent wetting cycles provided some healing to the cracks that developed in the first wet-dry cycle. However, these cracks remained as potential failure zones. When the subsequent drying cycles started, cracks appeared at the low strength locations that were associated with the earlier cracks. CIF increased to 5\% (the value obtained in the first wet-dry cycle) immediately in the second and third cycles (Fig. 5) and increased further as the cracks became wider.

Subsequent to the compaction-dry and wetdry cycles, penetration of cracks in Soil 1 was further studied. A cross-section through the soil that shows a vertical diagram of cracks is presented in Fig. 9. Vertical cracks were present in all three lifts used for compaction of the soil. The thickness of each layer was approximately $60 \mathrm{~mm}$. There were three types of vertical cracks:

1. cracks that penetrated the entire upper layer and continued into the lower layers;
2. cracks that penetrated the entire upper layer but did not continue into the lower layers; and 3 . cracks that penetrated each layer partially.

The total number of cracks in the upper layer exceeded the number of cracks in the lower layers. The dimensions (width and depth) of cracks formed in the upper layer were larger than those in the lower layers. Some cracks penetrated the entire thickness of the compacted soil. Cracks that penetrated the entire thickness of the sample were also observed for Soil 2. However, cracking did not penetrate the whole thickness of the sample for Soil 3. This sample was left in the tank for an extended period of time (over 2 years). Water poured directly over the cracks did not reach the bottom of the sample at the end of this period. It is believed that high sand content in this soil allowed for formation of relatively large pores in this soil. The water in these pores drained/ evaporated easily without allowing the formation of high suctions and extensive cracking.

Fig. 8. (a) Soil 2 at the end of the compaction-dry cycle, $\mathrm{CIF}=0.41 \%$. (b) Soil 2 subsequent to the first wetting period, $\mathrm{CIF}=0 \%$. (c) Soil 2 at the end of the first wet-dry cycle, CIF $=5 \%$. (d) Soil 2 subsequent to the second wetting period, CIF =0\%. (e) Soil 2 at the end of the second wet-dry cycle, CIF $=6.9 \%$. (f) Soil 2 subsequent to the third wetting period, CIF $=2.3 \%$. (g) Soil 2 at the end of the third wet-dry cycle, $\mathrm{CIF}=6.7 \%$. 

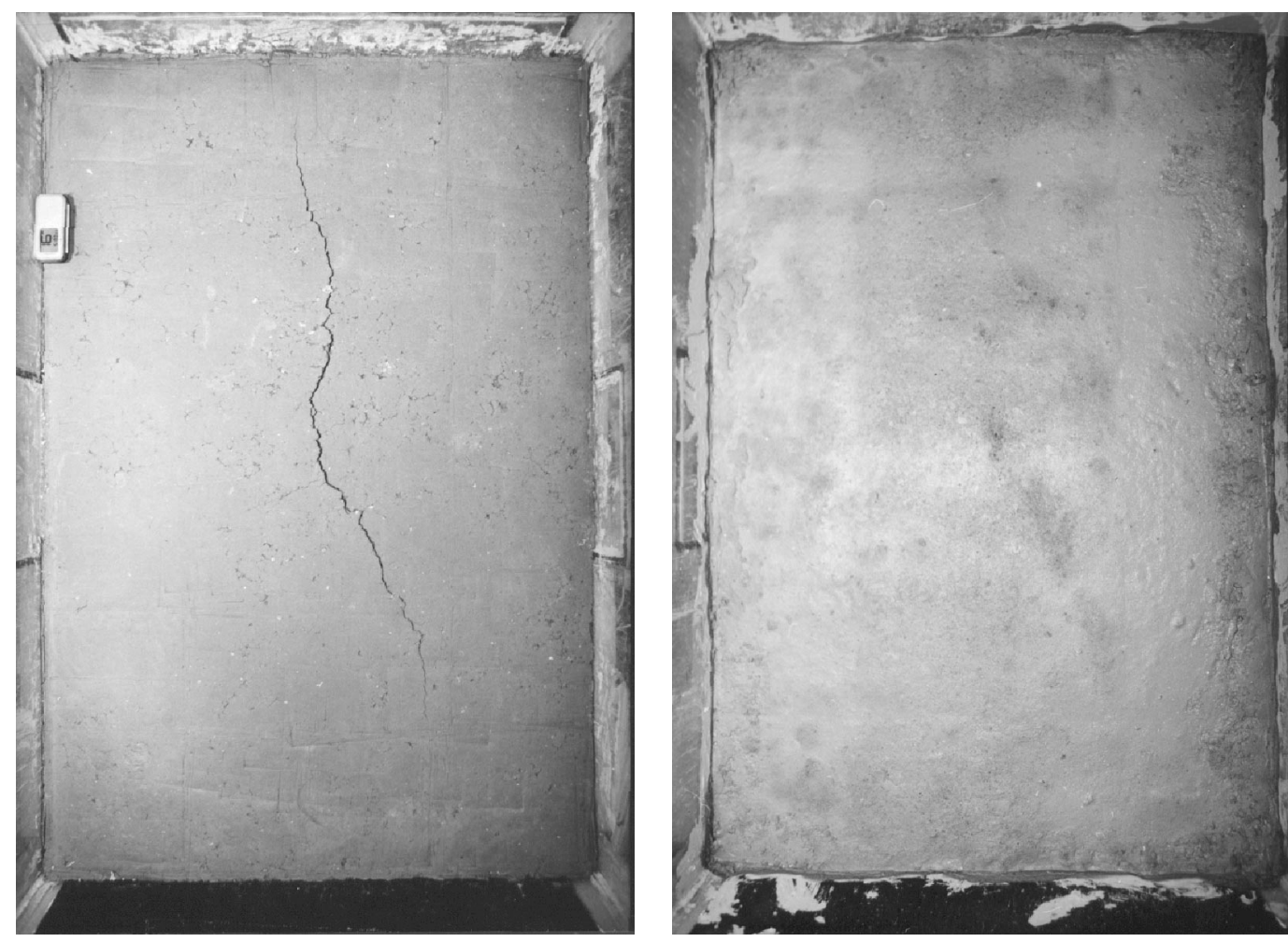

(a)

(b)
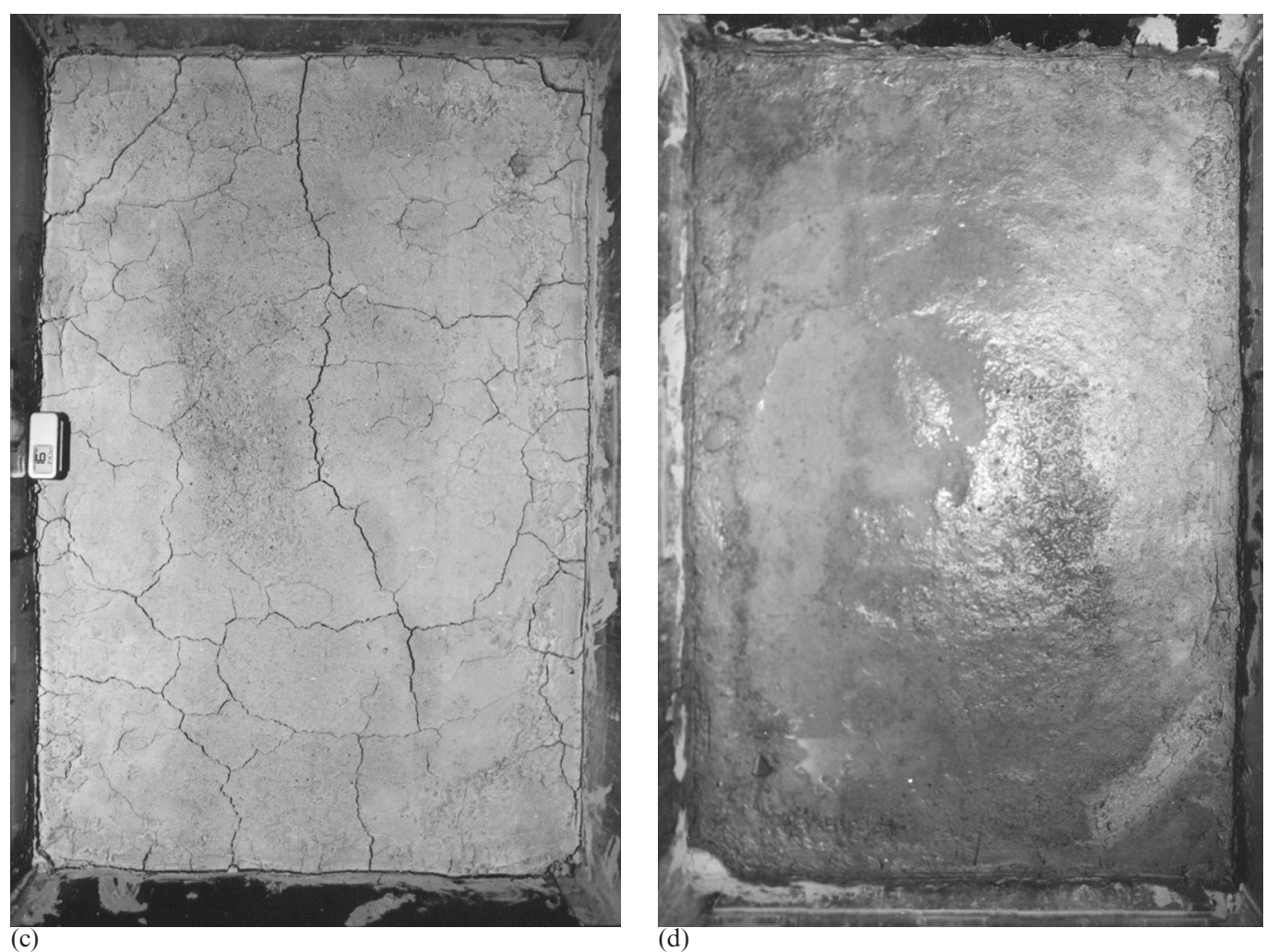

Fig. 8. For legend, see previous page. 


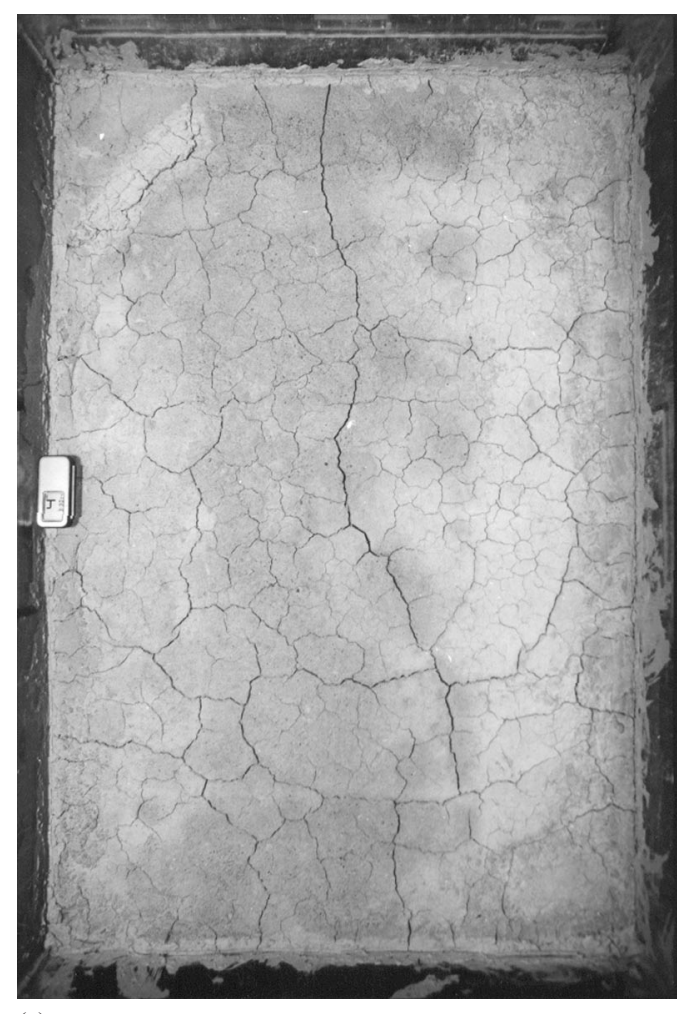

(e)

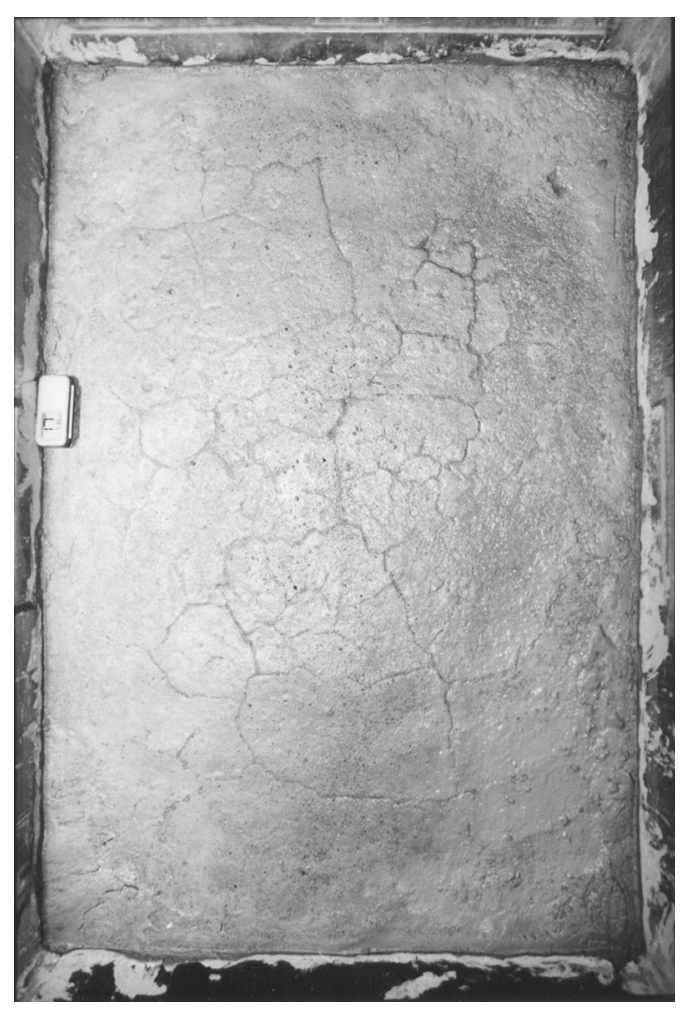

(f)

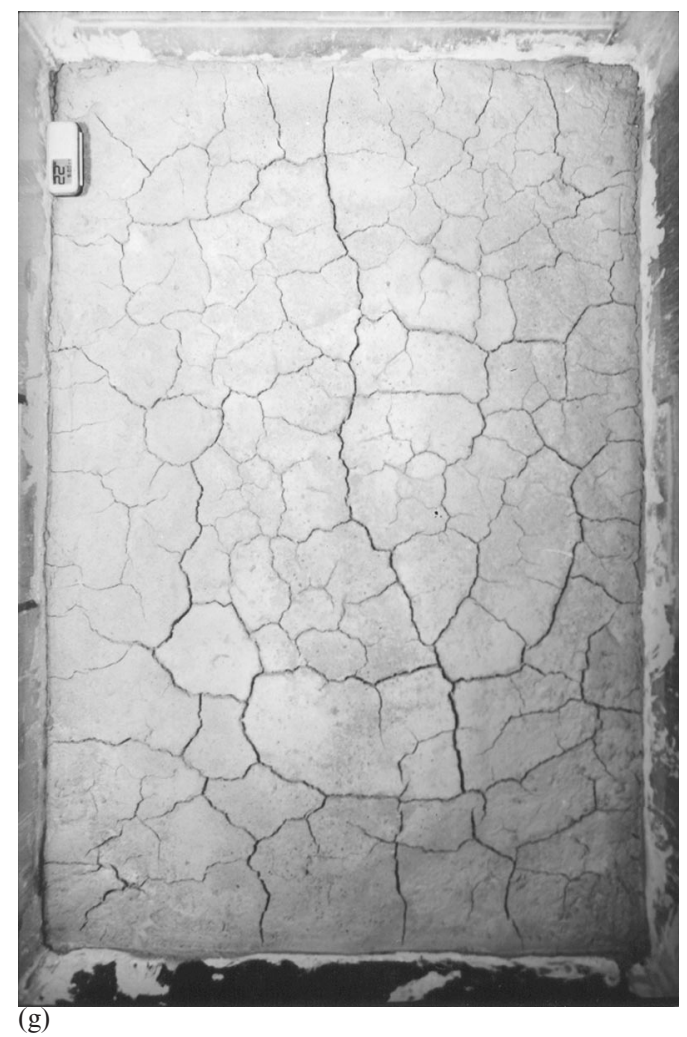

Fig. 8. (continued) 


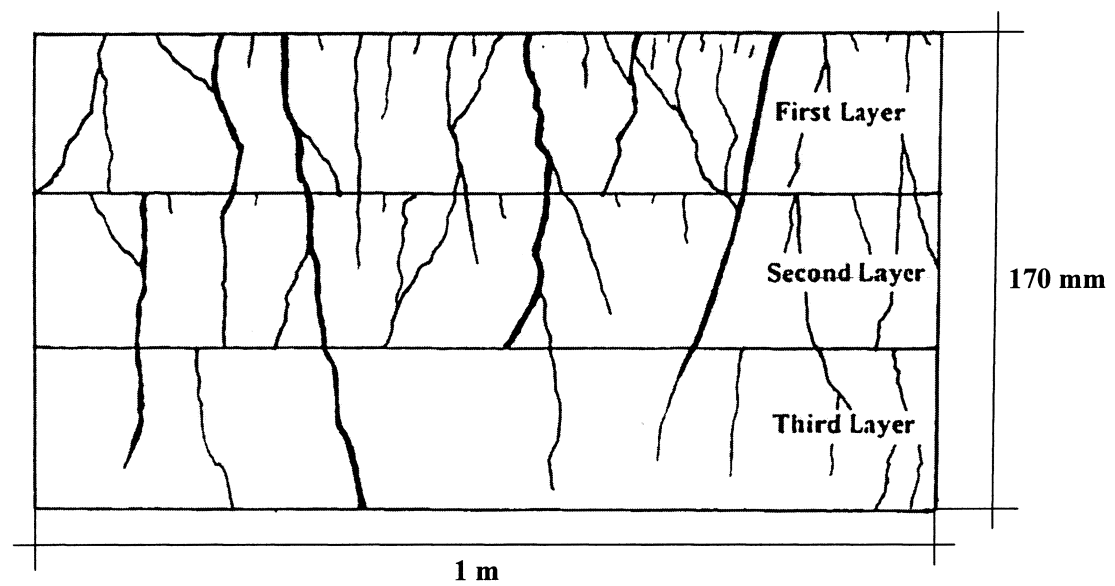

Fig. 9. Vertical crack pattern in Soil 1.

\section{Summary and conclusions}

Desiccation cracking was investigated in three compacted landfill liner soils obtained from southeast Michigan. The soils had low plasticity with varying fines content. Large-scale samples of the soils were subjected to wetting and drying cycles. Surficial dimensions of cracks and soil suctions were monitored during wetting and drying cycles. The extent of cracking on the surface of the soils was quantified using the CIF. All of the soils were subjected to a compaction-dry cycle and a subsequent wet-dry cycle. An additional sample of Soil 2 was subjected to a compaction-dry cycle and three wet-dry cycles.

It was observed that fines content in the soils affected the cracking behavior significantly. The greatest amount of cracking was observed in the soils with the greatest amount of fines fraction and the least amount of cracking was observed in the soil with least amount of fines fraction. The extent of cracking was not correlated directly to the PI of the soils used in this study. Fines content was a better indicator of cracking than plasticity. Suctions also increased faster in the soils with the high fines content. Small pores were formed in the soil with high fines content, which allowed for the development of high suctions in the soil.

In addition, it was observed that cracking subsequent to wetting was greater than cracking subse- quent to compaction. The CIF for wet-dry cycles were significantly greater than the CIF for compaction-dry cycles although high suctions were measured during both cycles. The extent of cracking is a function of both the amount of water in the soil at the onset of drying and suction attained during drying. The extent of cracking was observed to be more directly correlated to water content than suction. At the beginning of the compactiondry period the soil strength is near maximum for the given compaction conditions. This high strength results in a high resistance to cracking, as the soil can resist the large tensile stresses associated with high suction values. Upon wetting, the soil experiences softening and a decrease in strength. Subsequent drying induces suction, which exceed the resistance of the weakened soils causing cracking at locations of decreased soil strength.

Subsequent to the addition of water to the soils (first wetting period), at the beginning of drying, cracking progressed significantly at relatively low suction. Critical suction (suction causing a significant change in CIF) was $<1000 \mathrm{kPa}$ in all of the tests. Cracking did not progress significantly as the suction in the soils increased to $6000 \mathrm{kPa}$. For Soil 2, in the test with multiple wetting and drying cycles, the extent of cracking (i.e. CIF) did not change significantly after the second wet-dry cycle. The CIF was essentially same subsequent to second and third cycles. Irreversible changes occur in the 
fabric of clay soils during the first drying cycle (Yong and Warkentin, 1975). Upon wetting, the soil experiences weakening and a resulting decrease in strength. In the multiple cycle tests, wetting provided some healing to the cracks that developed in the first cycle. However, these cracks remained as weak zones, and with the subsequent cycles these cracks re-opened and cracking progressed easily. It is believed that structural rearrangement of soil fabric diminished subsequent to the first wetting and drying cycle. Therefore, the extent of cracking did not change significantly after this cycle.

\section{Acknowledgements}

Funding for this study was provided by the National Science Foundation under Grants Nos MSS-9123563 and CMS-9713922. Dr Hong Mi conducted the large-scale tests and $\mathrm{Mr}$ Ahmet Ozman assisted in data analysis.

\section{References}

Al Wahab, R.M., El-Kedrah, M.A., 1995. Using fibers to reduce tension cracks and shrink/swell in compacted clay. In: Acar, Y.B., Daniel, D.E. (Eds.), Geoenvironment 2000. ASCE, New York, pp. 791-805.

Albrecht, B.A., 1996. Effect of desiccation on compacted clays. MSc. Thesis, Department of Civil and Environmental Engineering, University of Wisconsin, Madison, WI.

Basnett, C., Brungard, M., 1992. The clay desiccation of a landfill composite lining system. Geotechnical Fabrics Report, IFAI 10 (1), 38-41.

Corser, P., Cranston, M., 1991. Observations on long-term performance of composite clay liners and caps. Proceedings of the Conference on Geosynthetic Design and Performance. Vancouver Geotechnical Society, Vancouver, Canada.
Daniel, D.E., 1991. Design and construction of RCRA/ CERCLA final covers. Soils Used in Cover Systems EPA/ 625/4-91/025.

Daniel, D.E., Wu, Y.K., 1993. Compacted clay liners and covers for arid sites. Journal of Geotechnical Engineering, ASCE 119 (2), 223-237.

DeJong, E., Warkentin, B.P., 1965. Shrinkage of soil samples with varying clay content. Canadian Geotechnical Journal 2 (1), 16-22.

Fredlund, D.G., Rahardjo, H., 1993. Soil Mechanics for Unsaturated Soils. Wiley, New York.

Holtz, R.D., Kovacs, W.D., 1981. An Introduction to Geotechnical Engineering. Prentice-Hall, Upper Saddle River NJ.

Kleppe, J.H., Olson, R.E., 1985. Dessication cracking of soil barriers. In: Johnson, A.I., Frobel, R.K., Cavalli, N.J., Pettersson, C.B. (Eds.), Hydraulic Barriers in Soil and Rock, ASTM STP 874. ASTM, West Conshohocken, pp. 263-275.

Mi, H., 1995. Kinematic wave formulation for flow through macroporous soil. Ph.D. Thesis, Department of Civil and Environmental Engineering, Wayne State University, Detroit, MI.

Miller, C.J., Mishra, M., 1989. Modeling of leakage through cracked clay liners - I: state of the art. Water Resources Bulletin, AWRA 25 (3), 551-555.

Miller, C.J., Mi, H., Yesiller, N., 1998. Experimental analysis of desiccation crack propagation in clay liners. Journal of the American Water Resources Association, AWRA 34 (3), 677-686.

Mitchell, J.K., 1993. Fundamentals of Soil Behavior. Wiley, New York.

Montgomery, R.J., Parsons, L.J., 1989. The Omega Hills final cap test plot study: three year data summary. Annual Meeting of the National Solid Waste Management Association. National Solid Waste Management Association, Washington DC.

Morris, P.H., Graham, J., Williams, D.J., 1992. Cracking in drying soils. Canadian Geotechnical Journal 29, 263-277.

Omidi, G.H., Thomas, J.C., Brown, K.W., 1996. Effect of desiccation cracking on the hydraulic conductivity of a compacted clay liner. In: Water Air and Soil Pollution vol. 89. Kluwer Academic Publishers, Netherlands, pp. 91-103.

Salim, I.A., 1994. Modeling the sorption and transport of heavy metals through landfill clay liners. Ph.D. Thesis, Department of Civil and Environmental Engineering, Wayne State University, Detroit, MI.

Yong, R.N., Warkentin, B.P., 1975. Soil Properties and Behaviour. Elsevier, Amsterdam. 